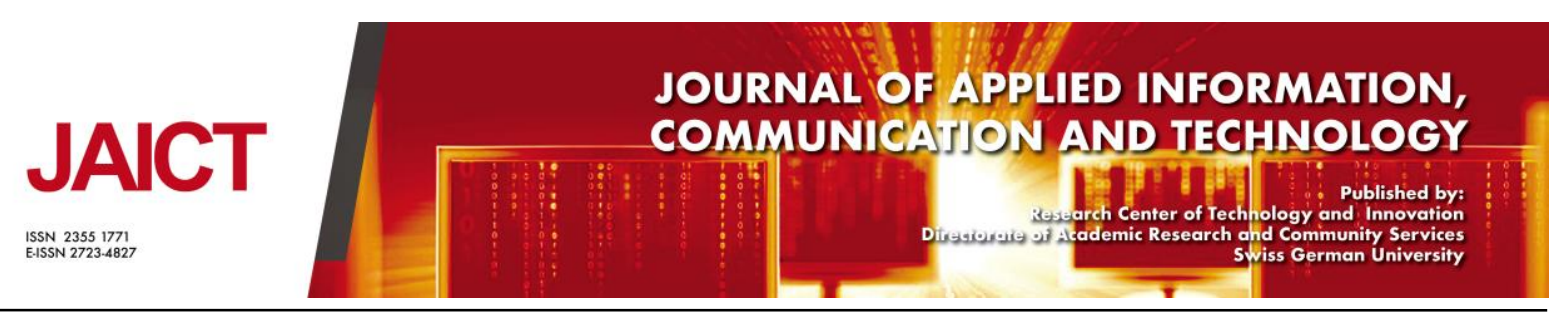

\title{
The Lack of Enforcement of the DRM Policy
}

\section{Stefanus Oliver, Tommy Winarta}

Department of Information Technology, Swiss German University, Tangerang 15143, Indonesia

\section{Article Information}

Received: 15 December 2019

Accepted: 12 January 2020

Published: 18 March 2021

DOI: $10.33555 /$ ejaict.v7i1.73

\section{Corresponding Author:}

Stefanus Oliver

Email: stefanusoliver@gmail.com

ISSN 2355-1771

eISSN 2723-4827

\begin{abstract}
In this digital era, numerous copyrighted items such as music and movies can be enjoyed online. However, our activities in enjoying those entertainments are also limited by the copyright law. Some contents are also protected by Digital Rights Management, which makes sure that the user who purchases the item is the only person who has the right to enjoy the content. All of these rules are obviously made to make sure that everything is in order. Therefore, those illegal activities can be brought to justice. However, the lack of communication might present an ambiguity to the users, and those users might unconsciously do illegal things that are previously forbidden. Other than that, the law itself has its own limitation in the aspect of execution and enforcement, causing pirated versions of a content can be found easily on the internet. This paper is going to review the current condition of the execution of the law regarding the DRM protected contents.
\end{abstract}

Keywords: DMCA, DRM, Piracy 


\section{Introduction}

\subsection{Main Problem}

In this digital era, piracy has become a major issue. Piracy is actually a violation of the copyright law. The law itself is unique from one country to another. Nowadays, movies and musics can be enjoyed much more freely with the help of the advanced network protocols. For example, streaming music is now possible, while physical audiophile was the only choice for people to enjoy music in the past. However, this fact blurs the line of right and wrong as there is almost no limitation on the internet.

Anybody can share his or her music, or even download one. Unfortunately, these kinds of actions might seem legal in nature, but it is actually illegal. Moreover, companies could lose an enormous amount of money. As the technology advances over time, there are more way to enjoy commercial items for free. For instance, with the help of files hosted on servers spread through the world or even peer-to-peer file sharing. Furthermore, according to the study conducted by the Business Software Alliance in 2011, 57\% of computer users admitted that they use pirated software, which means that more than half of the users in the world actually supports piracy (http://globalstudy.bsa.org/2011/). Ironically, the law is there, it just needs to be well executed.

Digital Rights Management (2.1) becomes one of several ways to suppress piracy. It is a policy stated by the vendors to control the rights of every consumer about the file that has been purchased. The files are mostly can only be used by using a specific platform. For example, movies that are downloaded through the iTunes can only be viewed by iTunes itself and or by using Apple devices. These so-called DRM-protected items sure has put some ground rules about what to do with the file.

The policies that control Digital Rights Management are mostly ambiguous in the eyes of people. Furthermore, communication and better application of the law is needed to bring these problems to order. Other than that, there are also lots of controversial views regarding this problem. Some people might think that "they pay, they should be able to enjoy it anywhere", while others support it. Besides, some people who download musics, movies, or others on their favorite website, they do not know that it is illegal. Perhaps some of them have known, but they do not want to care because they could think about nobody knows and who would check the originality.

Despite of these issues, as the time goes on, companies have started to distribute their files with DRM-free on the labels for example when people purchase musics on iTunes or on Amazon. However, piracy is not dead. And if any, DRM might worsen this problem. Lack of communication as well as enforcement of DRM ceases to bring the law to the best outcome.

\subsection{Problem Background}

\subsubsection{The Lack of the Law Enforcement}

The main shortage of law enforcement is the occurrence of the controversial DRM. The question that gives people choices between we should or we should not be trapped in a DRMprotected world is pretty tricky. On one side, we need to keep the content distributors prosperous. On the other side, the DRM is seen as the barrier that keeps the users to be unsatisfied. 
According to the Times Online, 800 pirated songs could be found in average teenager's music player or nearly the half of the teen's music library. This number surely needs to be reduced. The debate whether DRM is the right solution to battle piracy has been going on for years and the result has not been conclusive. One of the most famous effort to show which is better was done by an American comedian, Louis C.K.; he stepped on and sold a DRM-free movie of his show at the Beacon Theater for just $\$ 5$. By paying as low as $\$ 5$, the video can be watched anywhere without any rules as many times as they want. This resulted a grand success as much as $\$ 250,000$ that was earned just in the first 12 hours. This shows that there are still many people still pay for their own entertainment and that DRM is not always the answer to defeat piracy.

Moreover, the small people have not won the digital war yet. An example is shown in the Napster case. Napster is a service created by Shawn Fanning, which includes a server that indexes its users' media files and enables all of its users to share music files freely with no fee. The music that is distributed through Napster are DRM-free items that can be distributed to everyone freely, while those files are actually copyrighted files. This is known as peer-to-peer file sharing, which is applied by torrent service, a service that is banned in some countries. The service supports the statement which says that downloading copyrighted music files is allowed as it is being used in a non-profit activity. Many companies such as Universal Music Group, Sony Music Entertainment, EMI, and Warner Music Group went against Napster in court which resulted the shutdown of Napster.

From the case above, it is obvious that the law sure took the Napster case seriously. However, there are still numerous file sharing sites or other services that may enable people to download copyrighted items illegally and they have not been judged in the Napster case. This shows that the law is not sufficient in managing the growing parasite that is piracy; the law needs to be repaired to catch up with the increasing rate of digital piracy. DRM sure is one of the efforts to take the battle to the next level, however, it is unfortunate that without the proper execution of the law, it is just words on a paper.

\subsubsection{The Lack of Communication}

The main cause of the lack of communication is unintentional piracy. It is not a commonly known fact which says that downloading copyrighted musics or movies from foreign file hosting is a crime. Numerous file hosting such as 4 shared, indowebster, and sendspace still become the choice of most people to download entertainment contents. However, most people who actually download the data, they do not know that he or she is actually breaking the copyright law and it is illegal.

Other than that, DRM-free items are still perceived as data that can be shared with others. For example, tracks that are sold on iTunes, which are mostly DRM-free, they are copied in numerous gadgets. The questions that are still not answered is about people are able or not able to share it with their family or their friends and about anything that makes it different with uploading it on the internet. These questions may seem as an ambiguity to some people. Therefore, creating a gray area in using those contents, while there is actually only right or wrong.

In those two cases above, the ironic part is that they do not really know what they are actually doing. The law exists, but it is not known to them. This might be interpreted as they are actually the judge, while the law actually goes against it. For example, as stated in Indonesian's Cyberspace Law: 
"Pasal 72 ayat (2), kemudian menyatakan, bahwa bagi yang sengaja menyiarkan, memamerkan, mengedarkan, atau menjual kepada umum suatu ciptaan atau barang hasil pelanggaran hak cipta atau hak terkait sebagaimana dimaksud pada ayat (1) dipidana dengan pidana penjara paling lama 5 (lima) tahun dan/atau denda paling banyak $\mathrm{Rp} 500.000 .000$,(lima ratus juta rupiah)." which explicitly says that a user who infringes the copyright law by sharing files can be fined with the maximum amount of 500,000,000.00 IDR. Also, another example can be found in the United States of America's DMCA, which protects the copyright owners:

A. No person shall manufacture, import, offer to the public, provide, or otherwise traffic in any technology, product, service, device, component, or part thereof, that-

- is primarily designed or produced for the purpose of circumventing protection afforded by a technological measure that effectively protects a right of a copyright owner under this title in a work or a portion thereof;

- has only limited commercially significant purpose or use other than to circumvent protection afforded by a technological measure that effectively protects a right of a copyright owner under this title in a work or a portion thereof; or

- is marketed by that person or another acting in concert with that person with that person's knowledge for use in circumventing protection afforded by a technological measure that effectively protects a right of a copyright owner under this title in a work or a portion thereof.

\section{B. As Used in This Subsection}

- to "circumvent protection afforded by a technological measure" means avoiding, bypassing, removing, deactivating, or otherwise impairing a technological measure; and

- a technological measure "effectively protects a right of a copyright owner under this title" if the measure, in the ordinary course of its operation, prevents, restricts, or otherwise limits the exercise of a right of a copyright owner under this title."(n.p).

Both laws are strict against copyright infringement. As stated by Alicia Holfer in her study about the relationship between DRM and DMCA, "Users of DRM should remember that the closer DRM can be linked to copyrighted digital content, the more likely it will be protected by the anti-circumvention provisions of the DMCA", internet users should be aware of the actions they take in enjoying contents that is protected by DRM.

\subsection{Problem Identification}

From the main problem, we identify some problems that are connected each other and could be explained. There are so many questions that resides in our mind to observe and search to know what the answers are. The materials that could be identified are about how people think about downloading freely, about the law that exists, all about websites for sharing files, about something that has already occurred, and others.

Firstly, we can identify problems that occur about the intellection of people. It is true or not, people who download those files on the internet freely, they do not know if it is illegal. In addition, it is true or not that doing that is illegal or not. 
Secondly, we know there are so many websites on the internet which have a function to share files, specifically, to share music and movie files. We could observe that they are legal or not. We also could search to know something that could be their main purpose outside to share those files. We also want to know about the fact between true or false that authorities do not know the presence of those piracy websites. If they do not know, we also want to know about what is done by the authorities that control this case. If they know, we want to know the reason why they do not give a punishment or anything like that.

Thirdly, we know that basically, musics and movies on piracy websites come from someone who pays and then, he or she shares them. We could observe why they want to do that and what the advantages that they could get by doing that. We are also curious to know what something that becomes their motivations and they know about piracy or not.

Fourthly, we know the existence of iTunes, a place to get music and movie files by purchasing them first. Something that becomes our curiosity is iTunes provides the DRM-free for anyone who downloads music on iTunes. They could share it to their Smartphones and their laptops after paying for it. It also becomes a possibility to share it to their friends. The question is it is legal or illegal because DRM-free, that is known by users, after they purchase for it, it belongs to them and nothing could interfere them to do with it. Even if they can share it on piracy websites, they will never think about they are false. This also becomes our reason to make this paper because the lack of communication that is done by the DRM-free,

Fifthly, we also know about what happened with Napster. The fact that Napster has been closed raises the question why does the other file sharing sites have not been banned permanently. While some countries have actually blocked multiple blacklisted sites with the help of the DNS, other countries have not done the same thing thus making the action not maximum in effect.

Without proper execution, pirated-version of copyrighted contents can still exist on the internet. Therefore, a move has to be made to exterminate this issue, an action that can actually make the law much more effective and more global in effect. It also becomes our question in our mind, why all the other piracy websites such as 4shared, indowebster, and others do not get a penalty like Napster. Back to the identification in advance, it is true or not that the existence of the others is not known by the authorities, thus they are not followed up and get an action by the authorities.

The last but not least, we could make an observation of the law that exists. We know about the DMCA (2.2), but we want to know that DMCA has been being implemented well or not. Then, we also want to know the law that exists such as DMCA in other countries, it exists or does not. If it exits, we also want to know that it has been implemented well or not. If it does not exist, we want to know the reason and why the authorities do not want to care with it. It also becomes our main thing to discuss about the lack of the law enforcement itself.

That is all about the problem that we could identify so far. In this paper, something that becomes the most important thing that we want to give is some methods to solve these problem step by step. 


\subsection{Limitation}

To discuss and explain this main problem need really long period and many researches to observe. Besides, we have a limitation of time and condition to observe this problem completely. Therefore, we only could explain the main things with some steps to solve them.

We are going to recommend some techniques to solve the lack of communication and the law enforcement based on the ambiguity in public thinking. We could observe about DRM that is implemented by the DMCA. It is about how to realize the piracy website. There are some ideas to solve the lack of communication and the law enforcement, a better explanation about DRM-free, learn from Napster case, and persuade people to participate in protecting the copyright.

Talking about piracy is too wide. Therefore, in this paper, we will focus on music and movie that also based on the source and the content of this paper. Besides, this case has occurred in some countries, but the time that exists is too limited, we focus on what some cases that already and still happen in Indonesia.

\section{General Review}

\subsection{DRM}

DRM stands for Digital Rights Management. Generally, DRM is a class of technologies that are used by hardware manufacturers, publishers, copyright holders, and individuals with the intent to control the use of digital content and devices after the sale.

DRM is divided into two modes. They are called DRM free and DRM protected. DRM free is able to be shared. DRM protected is not able to be shared because all of policies are managed by the company. DRM is implemented when we are downloading anything on the internet.

\subsection{DRM-free contents}

DRM free is given in order to make users could save or share the file that has been downloaded on another device. For example, when we download a music file from iTunes, the company gives the users an availability to save the downloaded files on their mobile phones or another on their device.

\subsection{DRM-protected contents}

DRM protected is given because the company does not want the piracy occurs. Despite when we could save the downloaded music file from iTunes, but when we download a movie file from iTunes, we could not be able to save or share the file. We could watch the downloaded movie that has been downloaded only on iTunes itself.

\section{4. $D M C A$}

DMCA stands for Digital Millennium Copyright Act. DMCA is a law that is implementing the DRM concept in the United State. It has a good main function to criminalize production as well as dissemination of technology, also devices, or could about services intended to circumvent measures that we know with the name DRM that manage the access to every copyrighted work. "It also criminalizes the act of circumventing an access control, whether or not there is actual infringement of copyright itself. In addition, the DMCA heightens the penalties for copyright infringement on the Internet" (n.p). 


\subsection{Piracy Websites}

Piracy website means the websites that give and share pirated files that could be downloaded by all mankind such as pirated music and movie files.

\section{Methodology}

The main backgrounds are the lack of communication and the law enforcement. To prove that the backgrounds are valid and based on a true case, we do an interview. We do an interview with teenagers between 13 until 19 years old that live in Indonesia, exactly in Jakarta. We give 5 questions to answer in order to know what they feel, know, and experience about the case we try to solve. We ask them by using Indonesian language to communicate easily on a social media called LINE chatting because the limitation of our time and place.

We do the interview with teenagers because most people who involve in this case that has a connection with entertainment contents are teenagers. Most of them love to hear musics and watch movies, even a quote says that music becomes a part of their life. Most of teenagers even also post the quote on their social media, any kind of social media either in a written quote or a picture.

In order to get valid result, we think that we have to get many persons who want to answer our question. In this era, some people are too bored to read long questions, moreover, if they think that they have to answer with long sentences. To make it easier for them, we asked by using yes or no questions. The questions that we use to do the interview are,

a. Are all of the songs on your mobile phone and computers had been downloaded freely and obtained by using Bluetooth?

b. Have you ever downloaded a song or movie by purchasing first, like on iTunes or others?

c. Have you ever heard or even known about DRM or Digital Rights Management?

d. Have you known about the existence of the copyright law in Indonesia?

e. Do you know that downloading musics or movies freely are categorized as a piracy?

After we ask the five main questions, then we continue to ask deeply about their opinion, and even some of them ask back to us because some of them do not understand about some questions. We think that by getting these surveys we could prove the lack of communication and the law enforcement in Indonesia about copyright against piracy. The first three questions are connected with communication and the last two questions are connected with the law enforcement.

\section{Discussion}

The five questions are asked simultaneously and sequentially for 110 people. The first question is about all songs and movies that exist on their mobile phones and computers were obtained freely from the internet and Bluetooth, or not. The second question is about their experience of downloading musics or songs by purchasing them first, like if they download them on iTunes. The third question is about their knowledge about what DRM itself is. The fourth question is about their knowledge about the copyright law in Indonesia. The last question is about their opinion based on the fact that downloading entertainment contents freely is categorized as piracy or not. 
People who say yes $\mid 0$ People who say no

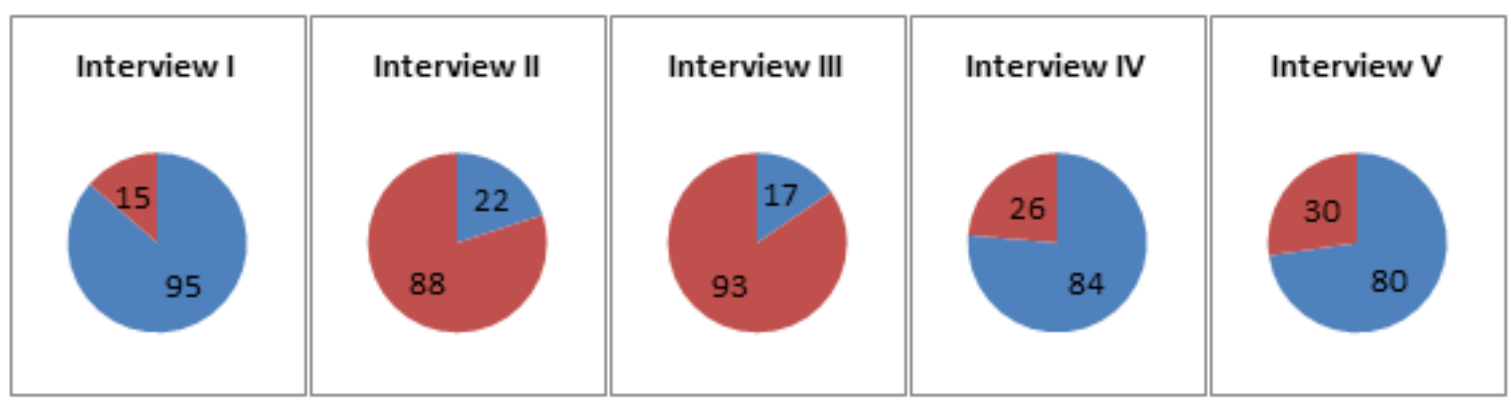

Figure 1. The Percentage Diagram of the Result of the Interview

For the first interview question, 95 of 110 people said yes, it is true that all of the songs on their mobile phones had been downloaded freely and obtained by using Bluetooth. Even, one of them asked me, "Is there any song that we have to pay?" It shows us that approximately $87 \%$ of them prefer downloading musics and movies freely and getting some of them by using Bluetooth from their friends.

The reason why they prefer doing that thing is they do not know that the songs and movies that they want to hear should be paid first to appreciate the maker. Besides, it becomes their ambiguities that if they get a file from their friends who initially download by purchasing, the file that is shared is legal or illegal.

For the second interview question, 22 people of all had ever downloaded entertainment contents on iTunes or others by purchasing them first with minimum one time they download, by purchasing, so they are categorized as the persons who had been downloaded by purchasing. However, some of them who make a purchase in downloading the contents, not all of the songs and the movies that they have on their mobile phones are fully downloaded by purchasing, also most of their contents are obtained by piracy websites and by Bluetooth from their friends.

For the third interview question, only 17 people of all who know about what Digital Rights Management is. This absolutely proves that many people do not know about the existence of the DRM. As we explain, the existence of the DRM is exactly really significant. DRM sets the availability of entertainments contents. If many people do not know about it, so they will share the files with others and even if they had already known about the DRM, they will still share the files with their friends who ask. It occurs because DRM did not give the clear explanation, moreover about the DRM-free.

DRM-free gives an availability to the users to share files that have been downloaded by purchasing. However, the availability that is given is either to only share the files to mobile phones and laptops that is owned by the users only, or the users could share it to their friends or probably in public. That case that becomes our question and ambiguity in public. It occurs because the lack of communication that had been done by the DRM.

For the fourth interview question, it is good because 84 people of all, they have already realized and known about the existence of the copyright law in Indonesia. One thing that they know and understand about the copyright law is it sets that the entertainment contents could not be pirated physically or used without the permission from the owner or the person that 
connected. However, they do not know if the law also sets about the piracy that is absolutely illegal. Besides, we could see the law that is implemented, especially in Indonesia. We could see pirated DVDs are sold everywhere, the existence of piracy websites that make people able to download those contents freely, but they do not get any actions from the authorities. It shows that the lack of the law enforcement itself.

The law itself also needs some works. For example, in America, the DMCA (Digital Millennium Copyright Act) which controls the DRM actually does not exist without any unintentional negative impacts. For instance, a big number of customers who buys digital contents on the internet has been unsatisfied with policies that are stated by the companies that limits the clients' actions regarding the data. Other than that, the companies can just change their strategies in distributing the contents which might hurt the customers. For example, a sudden change of policy by iTunes in April 2004, which says that burning a playlist into the CD media is only legal for 7 times, down from the past number which was 10.

For the fifth interview question, 80 of 110 people, they have known that downloading musics or movies freely are categorized as piracy. It sounds good. However, if we compare with the result of the first question, there are 95 people who download freely, but 80 people have already known that if they do that, it means they do a piracy. Therefore, it occurs also because the lack of self-awareness. No matter, they have already known, they still download freely because most of them think that there are free contents, why they should pay. That is why self-awareness becomes the most important thing that must be followed with the strongest law enforcement with clear communication in public.

\section{Recommendations}

As the technology advances, there are more methods that can be used to break the rules. Therefore, an improvement is needed in every aspect possible so that we can keep up with the pace of the growth of piracy. The government and its extension take a huge role in creating and implementing the copyright law, therefore it is recommended for the law enforcers to make more effort in spreading the word about the existing law. For example, rather than only putting a disclaimer about potential crime that the client might do on DVDs, digital contents are also being put in the main focus of this kind of action by alerting the user about what the user can do with the data that was downloaded. Other than that, there has to be a clear distinction about the concept of fair use and piracy itself in the law so that people would not misinterpret their rights in using the content.

The action that can be taken does not always has to be from the law itself. For example, physical contents can also be a great alternative for people who would like to ensure their ownership of the item that the owner bought. Moreover, most of the contents can be enjoyed anytime and as many times as the owner wants. Other than that, streaming the contents online is one of the better ways to enjoy contents online. Netflix, Hulu, or Spotify are the examples of products that enables the user to watch entertainment contents online without downloading it, the files are not stored in the physical drive, thus minimizing the risk of piracy by restricting the ability to copy the file directly.

One thing that becomes the most important thing is we are as an individual could participate in copyright protection by purchasing for those entertainment contents and not downloading from piracy websites. Conceive and imagine we are as a person who has the creation, absolutely we do not want our creation is hijacked. Therefore, appreciate the creations of 
others, so that we would be appreciated more by others. As the next generation, for what we could do is to have a good self-awareness to control ourselves. As the next generation, we could do self-introspection. Start from today to think about something that could keep and uphold the protection of copyright as the younger generation.

\section{Conclusion}

The main problem is about the ambiguity in the mind of people. The lack of communication and the lack of law enforcement are two of the factors that cause this problem in the society. Minimal communication of the law itself makes people do not realize that download copyrighted entertainment contents on the website freely is illegal and making them question their action regarding a content that is tied with DRM. Other than that, the law lacks of proper execution, which causes the existence of many piracy websites and some country do not even implement the similar copyright law as other countries.

From the research, 95 of 110 people said that all of the songs on their mobile phones had been downloaded freely and obtained by using Bluetooth. 22 people of all had ever downloaded entertainment contents on iTunes or others by purchasing them first with minimum one time they download, by purchasing, so they are categorized as the persons who had been downloaded by purchasing. 17 people of all who know about what Digital Rights Management is. 84 people of all, they have already realized and known about the existence of the copyright law in Indonesia. 80 of 110 people, they have known that downloading musics or movies freely are categorized as piracy.

These results show that there are 95 people who download freely, but 80 people have already known that if they do that, it means they do a piracy, and they still do that. It also shows why self-awareness becomes the most significant thing that must be followed with the strongest law enforcement with clear communication in public.

As the result, we recommend some ways to solve these problems. The recommendations are watching entertainment contents online without downloading it, but by purchasing it also with much cheaper price than download by purchasing, own the physical contents such as DVD and others that are in original context, looking into DMCA that is implemented well, learning by Napster case, and get better explanations by DRM, especially about DRM-free.

We also hope for the future as the next generation, for what we could do is having a better self-awareness to control ourselves, to not do a piracy on the internet. We are the next generation, we will decide. Start from today to think about something that could keep and uphold the protection of copyright as the younger generation. Try to purchase what we want if it asks to be paid. Appreciate the works of others, so your works will be appreciated more. Think what will you feel if your works are pirated, so stop to pirate the works of others.

\section{References}

DMCA Sec. 1201 (1999). Circumvention of copyright protection systems. Retrieved from http://cyber.law.harvard.edu/openlaw/DVD/1201.html\#a.

EFF (2010). Retrieved from https://www.eff.org/wp/unintended-consequences-under-dmca 
Hoffer, A. (2011). A Matter of Access: How Bypassing DRM does not Always Violate the DMCA Retrieved from http://digital.law.washington.edu/dspacelaw/bitstream/handle/ 1773.1/1049/7WJLTA013.pdf?sequence=5.

Louis. (2011). Statement from Louis C.K. Retrieved from https://buy.louisck.net /news/astatement-from-louis-c-k.

Macworld Staff, Macworld. (2009). ITunes Store and DRM-free music: What you need to know. Retrieved from http://www.macworld.com/article/1138000/drm_faq.html.

Mies, G. (2008). 10 Best (and DRM-free) Online Music Stores. Retrieved from http://www.techhive.com/article/155512/online_music_drm.html.

Wikipedia, the free encyclopedia. (Last modified: 2014, February 23). A\&M Records, Inc. v. Napster, Inc. Retrieved from http://en.wikipedia.org/wiki/A\&M_Records,_Inc._ v._Napster,_Inc.

Wikipedia, the free encyclopedia (Last Modified: 2014, May 14). Digital Right Managements. Retrieved from http://en.wikipedia.org/wiki/Digital_rights_management.

Wikipedia, the free encyclopedia (Last modified: 2014, May 11). Napster. Retrieved from http://en.wikipedia.org/wiki/Napster. 